\title{
Construction of Human Factor IX Expression Vectors in Retroviral Vector Frames Optimized for Muscle Cells
}

\author{
JIAN-MIN WANG, ${ }^{1}$ HONG ZHENG,${ }^{1}$ YUICHI SUGAHARA, ${ }^{1}$ JUN TAN, ${ }^{1}$ SHOU-NAN YAO, ${ }^{1}$ \\ ERIC OLSON, ${ }^{2}$ and KOTOKU KURACHI ${ }^{1}$
}

\begin{abstract}
Development of a highly refined human factor IX (hFIX) expression vector system is critical for establishing a durable hemophilia $B$ gene therapy. Here we report construction of a series of retroviral vectors and identification of an optimal basic structure and components for expressing hFIX in skeletal muscle cells. These vectors, which are derived from Moloney murine leukemia virus (MoMLV) with its enhancer sequence in the $3^{\prime}$ long terminal repeat (LTR) deleted, contained internal hFIX expression units inserted in forward configuration without or with a viral vector intron sequence (pdL or pdLIn vector frame, respectively) or in inverted configuration without a viral vector intron sequence (pdLi frame). Internal expression units contained a hFIX cDNA or hFIX minigene (hIXm1 or hIXm2) derived from the hFIX cDNA by insertion of a shortened first intron sequence of the hFIX gene. Regardless of the promoter and vector frame used, both hIXm1 and hIXm2 gave 10- to 14-fold higher hFIX expression compared to those with hFIX cDNA. Internal hFIX transcriptional control units of these vectors were composed of various promoters linked with or without the muscle creatine kinase enhancer (Me) sequence. Promoters tested included those of $\alpha$-actin ( $\alpha$ A775), $\beta$-actin ( $\beta A 280)$, cytochrome oxidase (CO1250 and CO650), myogenin (Mg1031 and Mg353), and Rous sarcoma virus (RSV). $\beta A 200$, which was derived from $\beta$ A280 by eliminating potential polyadenylation sites, was also tested. As extensively examined with the myogenin promoter, presence of one or multiple copies of Me in the vectors elevated the expression activity in myotubes by 4.5 - to 19 -fold over those without Me, but not significantly in myoblasts. Similar enhancements in expression activity with Me were also observed with other promoters, except those of RSV and CO. The latter two showed only modest enhancements in the presence of Me. As assayed with myotubes in culture, the general order of hFIX expression activity of various promoters

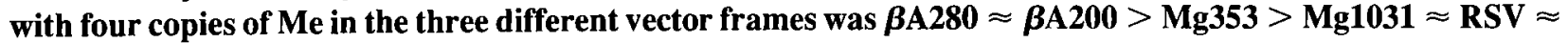
$\mathrm{CO650} \approx \alpha \mathrm{A} 775>\mathrm{CO1250}$. One exception was that CO650 showed significantly less activity in pdLi-type vectors than in the pdLIn vectors. Based on the systematic analyses of various structural components, a group of pdLi vectors consisting of $\beta A 200$, two to four copies of $\mathrm{Me}$, and $\mathrm{hIX} \mathrm{m} 2$ was identified to have the optimal basic vector structure to be used in retrovirus for hFIX expression in differentiated skeletal muscle cells. The present studies provide the critical first step for establishing a highly refined hemophilia $B$ gene therapy based on skeletal muscle-targeted hFIX gene transfer.
\end{abstract}

\section{OVERVIEW SUMMARY}

Skeletal muscle cells may serve as an efficient medium for systemic production of transgene products in a gene therapy. Retroviral vector constructs were prepared using hu- man factor IX minigenes, various muscle-specific or nonspecific promoters, and muscle creatine kinase enhancer. These vectors were tested systematically to determine an optimal basic structure for producing factor IX in mouse skeletal muscle cells. The basic retroviral vector structure

1Department of Human Genetics, University of Michigan Medical School, Ann Arbor, MI 48109.

${ }^{2}$ Department of Biochemistry and Molecular Biology, University of Texas, Houston, TX 77030. 
for an optimal expression of factor IX in skeletal muscle cells may contain an internal factor IX expression cassette composed of a $\beta$-actin promoter, muscle creatine kinase enhancer, and human factor IX minigene in a reverse orientation relative to the $5^{\prime}$ long terminal repeat.

\section{INTRODUCTION}

$S^{\mathrm{k}}$ Reletal muscles comprise a large portion of human and nimal bodies, and are easily accessible for various manipulations. Skeletal myoblasts can be prepared from muscle tissue biopsy samples and expanded in culture to large numbers (Webster et al., 1988; Rando and Blau, 1994). Intramuscularly implanted myoblasts genetically modified in culture not only fuse with the existing host myofiber cells or among themselves, generating new muscle cells, but also survive as muscle precursor cells (satellite cells) (Yao and Kurachi, 1993). Skeletal muscle has also been shown to have high systemic delivery efficiency of various transgene products (Yao and Kurachi, 1992). Accordingly, muscle-targeted gene transfer has been intensively studied for its potential application for establishing gene therapies for various disorders (Barr and Leiden, 1991; Yao and Kurachi, 1992; Bansal et al., 1994; Baque et al., 1994; Hamamori et al., 1995). The potential of myoblast-mediated gene transfer to be developed into a durable gene delivery method has been extensively tested for various genes such as factor IX (Dai et al., 1992; Yao and Kurachi, 1992; Yao et al., 1994), growth hormone (Dhawan et al., 1991; Dahler et al., 1994), erythropoietin (Hamamori et al., 1995), glucocerebrosidase (Bansal et al., 1994), and other proteins (Jiao et al., 1993). Muscle-targeted gene transfer may be achieved by various methods, such as in vivo direct gene transfer using viral vectors (Ragot et al., 1993; Vincent et al., 1993; Acsadi et al., 1995; Dai et al., 1995) and naked vector DNAs (Davis et al., 1993a,b; Manthorpe et al., 1993) or ex vivo gene transfer (myoblast-mediated gene transfer) (Barr and Leiden, 1991; Dhawan et al., 1991; Yao and Kurachi, 1992, 1994; Salvatori et al., 1993; Vitadello et al., 1994; Hamamori et al., 1995; Trivedi and Dickson, 1995).

For establishment of a durable gene therapy method, development of a highly refined gene delivery system has become a crucial issue (Miller, 1992a,b). Retroviral vector systems have been extensively used to introduce foreign genes into various target cells including skeletal muscle cells (Dhawan et al., 1991; Yao and Kurachi, 1992; Yao et al., 1991, 1994; Miller, 1992b). Most retroviral vectors used to date are derivatives of Moloney murine leukemia virus (MoMLV) (Miller, 1992a,b). Although its long terminal repeat (LTR) promoter is generally strong in various cell types and also can direct stable transgene expression in skeletal muscle cells (Yao et al., 1994), the LTR promoter is not differentiated muscle cell specific. Expression of foreign genes under its control is not elevated much upon myoblast differentiation. Transcriptional control units with various cell type-specific promoters and enhancers in retroviral vectors can confer cell-specific and persistent expression of the transgenes (Petropoulos et al., 1992; Anson and Occhiodoro, 1994; Dahler et al., 1994).

Recently, we reported that primary mouse skeletal myoblasts transduced with recombinant retroviral vectors containing a hu- man factor IX (hFIX) cDNA under control of the LTR or chicken $\beta$-actin promoter $(\beta A)$ with murine muscle creatine kinase (MCK) enhancer (Me) can express hFIX at a high level, equivalent to that observed for $\mathrm{C} 2 \mathrm{C} 12$ cells (established murine myoblast line) (Yao and Kurachi, 1992; Yao et al., 1994). The in vivo hFIX expression levels of the primary myoblasts were, however, significantly lower than those observed with $\mathrm{C} 2 \mathrm{C} 12$ cells in a similar experiment (Yao et al., 1994). It was concluded that the observed difference between the primary myoblasts and $\mathrm{C} 2 \mathrm{C} 12$ cells is likely due to their cellular properties, such as fusion efficiency and in vivo stability, rather than due to a possible promoter inactivation as reported by others (Palmer et al., 1991; Scharfmann et al., 1991; Dai et al., 1992). These observations strongly suggested the necessity for extensive refinement of two aspects of the muscle-targeted gene delivery system, the hFIX expression vector structure and the cellular procedures involved.

The present paper deals with the first phase of our intensive studies on the hFIX expression vector, defining its structural components and organization required for an optimal production of hFIX in differentiated muscle cells (myotubes). We have constructed a series of hFIX expression vectors in three different vector frames derived from MoMLV, with a battery of different muscle-specific and nonspecific promoters combined with $\mathrm{Me}$ and hFIX minigenes. They were constructed so that the hFIX expression cassette can be easily transferred into various other viral and nonviral vector systems for further testing. These vectors were subjected to systematic expression analyses with primary mouse skeletal myoblasts and myotubes, thus establishing the basic structure in retroviral vector frame for the optimal hFIX expression in muscle cells.

\section{MATERIALS AND METHODS}

\section{Construction of hFIX expression vectors}

Promoter Sequences: Muscle-specific and nonspecific promoters were prepared by excising from the previously prepared vectors, or by polymerase chain reactions (PCR) using 5' and 3' primers with $X h o$ I and Bam HI linker sequences, respectively, and genomic DNA or cloned DNA fragments as the templates (Table 1). PCR was carried out as previously described (Yao et al., 1994), and resulting DNA fragments containing various promoter sequences were digested with $X h o$ I and Bam $\mathrm{HI}$, purified by agarose gel electrophoresis, and inserted into various expression vectors at their Xho I/Bam HI sites. Specific procedures for preparation of each promoter sequence are described below.

A long myogenin promoter, $\mathrm{Mg} 1031$, which contains the sequence-spanning nucleotide $-1,013$ to +18 of the myogenin gene, was derived by PCR with a pair of primers and pMyol565CAT as the template (Edmondson et al., 1992) (Table 1). The PCR product was digested with Xho I and Bam $\mathrm{HI}$, generating $\mathrm{Mg} 1031$ with Xho I and Bam HI sites at its 5' and $3^{\prime}$ ends, respectively. A short myogenin promoter sequence fragment, $\mathrm{Mg} 353$, containing the region spanning nucleotides -335 to +18 of the myogenin gene, was prepared by removing the 5' half of $\mathrm{Mg} 1031$ (nucleotides - 1,031 through -334) by cleaving with $S m a$ I at nucleotide -334. A Xho I linker was then ligated at the Sma I site followed by Xho I digestion. 
Table 1. PCR Primers for Preparation of Promoter Sequences

\begin{tabular}{|c|c|c|c|c|}
\hline Promoter & Primer Sequence* & $\begin{array}{l}\text { Nucleotide } \\
\text { Position }\end{array}$ & $\begin{array}{c}\text { PCR } \\
\text { Template }\end{array}$ & Reference \\
\hline $\begin{array}{l}\text { Mgl031 } \\
\text { (Mouse) }\end{array}$ & $\begin{array}{l}\text { 5' forward: 5'-CAT CTC GAG TAC } \\
\text { AGG GGA ACG CCA GGG C-3' } \\
\text { 3' reverse: 5'-TAT GGA TCC CCC } \\
\text { AAG CTC CCG CAG CCC C-3' }\end{array}$ & $\begin{array}{l}\text { nt }-1013 \text { to }-993 \\
\text { nt }+18 \text { to }-3\end{array}$ & pMyol 565CAT & $\begin{array}{l}\text { Edmondson } \\
\text { et al., } 1992\end{array}$ \\
\hline $\begin{array}{l}\text { Co1251 } \\
\text { CO650 } \\
\text { (Calf) }\end{array}$ & $\begin{array}{l}\text { 5' forward: 5'-CCG CTC GAG GTC } \\
\text { CCT AGA CTG AGG CAC-3' } \\
\text { 5' forward: 5'-CCG CTC GAG CGA } \\
\text { CCT CCC GGG GCC AGC-3' } \\
\text { 3' reverse: 5'-CGC GGA TCC AGT } \\
\text { TGT AGG GCT GAG CTC CT-3' }\end{array}$ & $\begin{array}{l}\text { nt- } 1189 \text { to }-1170 \\
\text { nt- } 588 \text { to }-569 \\
n t+62 \text { to }+43\end{array}$ & pCOX8HCAT & $\begin{array}{l}\text { Lomax et al., } \\
1995\end{array}$ \\
\hline $\begin{array}{l}\alpha A 775 \\
\text { (Human) }\end{array}$ & $\begin{array}{l}\text { 5' forward: 5'-ACT GCT CGA GGT } \\
\text { GGC CCT CTG TGC GGT GG-3' } \\
\text { 3' reverse: 5'-CAC TGG ATC CGG } \\
\text { GTA GCT ACA ACT GCT ACT-3' }\end{array}$ & $\begin{array}{l}\text { nt }-689 \text { to }-672 \\
n t+86 \text { to }+66\end{array}$ & $\begin{array}{l}\text { Human } \\
\text { genomic DNA }\end{array}$ & $\begin{array}{l}\text { Taylor et al., } \\
1988\end{array}$ \\
\hline $\begin{array}{l}\beta A 200 \\
\text { (Chick) }\end{array}$ & $\begin{array}{l}\text { 5' forward: 5'-CCT CCT CGA GGG } \\
\text { CCC TTT TTT TTT TTG TGC } \\
\text { AGC GAT GGG GG-3' } \\
\text { 3' reverse: 5'-CAC GGA TCC TAG } \\
\text { GTC CCG CCC GCC GCG CGC } \\
\text { TT-3' }\end{array}$ & $\begin{array}{l}\text { nt }-1199 \text { to }-1174 \\
\text { nt }-1000 \text { to }-1018\end{array}$ & $\begin{array}{l}\text { pdLMe } 2 \beta A 280 \\
\text { IX }\end{array}$ & $\begin{array}{l}\text { Kost et al., } \\
1983 \\
\text { Yao et al., } \\
1994\end{array}$ \\
\hline
\end{tabular}

*The underlined sequences indicate restriction sites built into the PCR primers. The italic Ts in $\beta$ A200 5' primer sequence indicate they are different from the original gene sequence with adenine residues.

Bovine cytochrome oxidase $(\mathrm{CO} 8 \mathrm{H})$ promoter sequences were prepared by PCR using pCOX8HCAT containing bovine $\mathrm{CO} 8 \mathrm{H}$ $5^{\prime}$-flanking sequence as the template (Table 1) (Lomax et al., $1995)$. Long (1,251 bp) and short (650 bp) forms of the CO promoter, $\mathrm{CO} 1251$ and $\mathrm{CO650}$, were prepared by using either one of the two $5^{\prime}$ forward primers (corresponding at nucleotides $-1,189$ to $-1,170$ and nucleotides -588 to -569 ) and a common 3' primer (nucleotides +62 to +43 ) (Table 1 ).

Human $\alpha$-actin promoter ( $\alpha$ A775) was prepared by PCR using human genomic DNA as the template (Taylor et al., 1988) (Table 1). Because of the presence of an Xho I site at nucleotide -86 within the $\alpha \mathrm{A}$ promoter sequence, the PCR product was first digested with $B$ am $\mathrm{HI}$ and then subjected to partial digestion with $X h o$ I, thus obtaining $\alpha \mathrm{A} 775$.

A Rous sarcoma virus (RSV) promoter fragment was obtained from pERT9 (Invitrogen) as follows. A unique Xho I site present in the RSV promoter sequence contained in PERT9 was eliminated by Xho I digestion followed by blunt-ending and religation. A Sal I-Bam HI fragment ( $\sim 600 \mathrm{bp})$ containing the RSV promoter sequence was isolated from the resulting vector and inserted into pBluescript vector (Stratagene) at $\mathrm{Sal} \mathrm{L} / \mathrm{Bam} \mathrm{HI}$ sites, generating pBluescriptRSV. The Xho I/Bam HI fragment containing RSV promoter sequence was then generated by digestion of pBluescriptRSV with Xho I and Bam HI.

Chicken $\beta$-actin promoter ( $\beta$ A280, containing a region spanning nucleotides $-1,279$ through $-1,000$ ) (Kost et al., 1983) was derived from a hFIX expression vector, pdLMe2 $\beta A 280 \mathrm{hIX}$ (pre- viously named pdLMMBAIX), constructed in our previous study (Yao et al., 1994). A short form of the $\beta A$ promoter sequence $(\beta A 200)$ containing the region nucleotides $-1,199$ through $-1,000$ was prepared by PCR using this vector as the template and primers listed in Table 1 . The $5^{\prime}$ primer contained thymine residues replacing the adenine residues present in the original gene sequence at nucleotides $-1,197,-1,196$, and $-1,193$ (italics in Table 1) to disrupt potential polyadenylation site sequences. The $5^{\prime}$ forward primer contained $\mathrm{Xho} \mathrm{I}$ and $\mathrm{Apa} \mathrm{I}$ linker sequences in its $5^{\prime}$ end region, while the $3^{\prime}$ reverse primer contained Avr II and $\mathrm{Bam} \mathrm{HI}$ sequences. These sites were included to make the fragment versatile in transferring into other vectors.

$M C K$ Enhancer ( $M e$ ): The region (hereafter referred to as Me) spanning nucleotides $-1,351$ to $-1,050$ of the 5 '-flanking sequence of mouse MCK gene contains a strong musclespecific enhancer activity (Sternberg et al., 1988). A fragment containing two Me copies (Me2) was constructed by inserting two 301-bp Xho I fragments (a single copy of Me), previously prepared (Yao et al., 1994), into pBluescript vector at Xho I site in a tandem orientation. The Xho I site in between the two Me sequences was eliminated by blunt-ending. Fragments containing four copies of $\mathrm{Me}(\mathrm{Me} 4)$ in a tandem orientation was constructed in a similar manner by using $\mathrm{Me} 2$ as the starting fragment.

Vector Frames: Three different vector frames, pdL, pdLIn, and $\mathrm{pdLi}$, were used in constructing the hFIX expression vectors (Fig. 1A). 
A

pdL

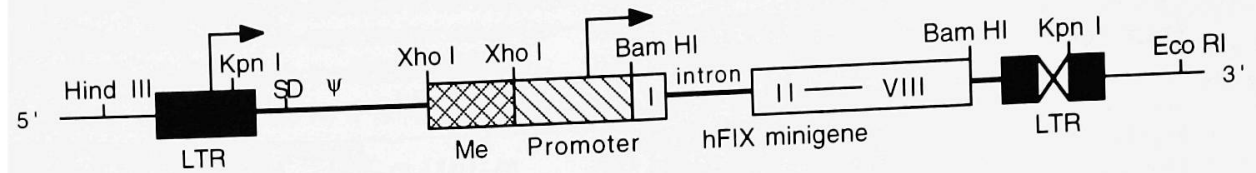

pdLIn

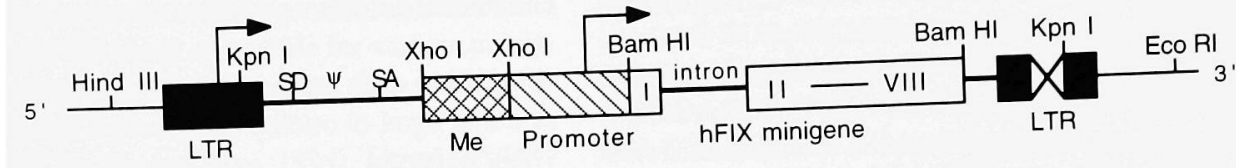

pdLi

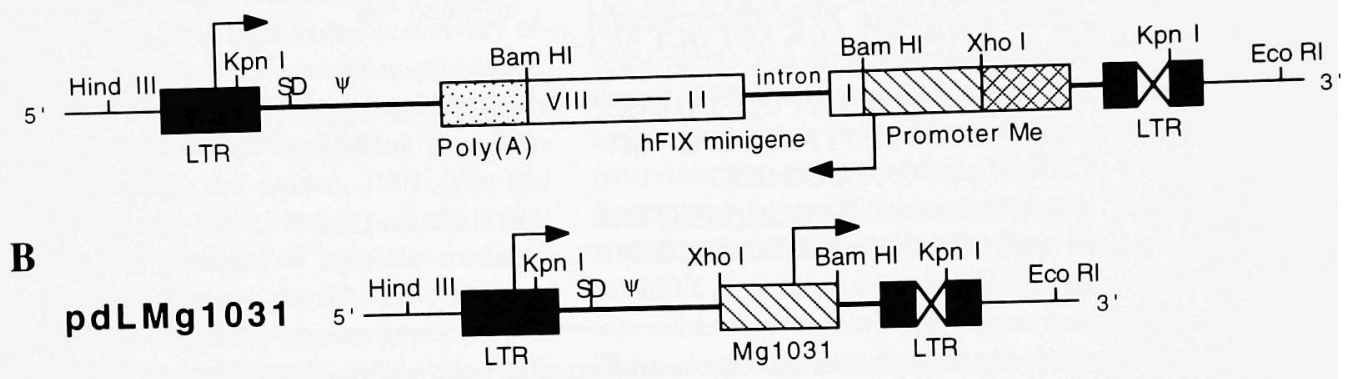

pMFG

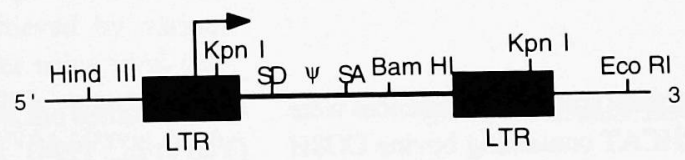

$\operatorname{pdL}(B B)$

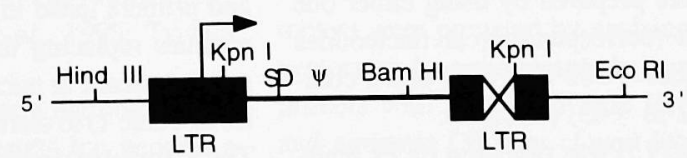

$\operatorname{Pd} L(X X)$

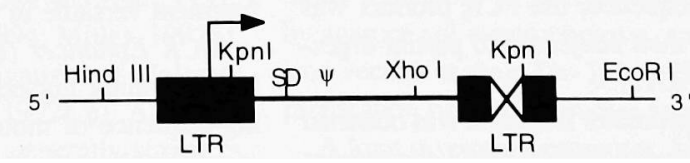

FIG. 1. A. Three basic retroviral vector frames used to construct new hFIX expression vectors. All vectors are derivatives of MoMLV. pdL indicates a vector frame with the $3^{\prime}$ LTR with its enhancer region deleted. pdLIn has the same structure as pdL, except that it is inserted with the MFG-derived vector intron sequence. pdLi has the same vector frame as pdL, except that the internal FIX expression unit is inserted in an inverted orientation with regard to the $5^{\prime}$ LTR. B. Intermediate constructs used for preparing pdLIn- and pdLi-type vectors. The unique Bam HI site in pMFG was converted to Xho I, and a Hind III-Xho I fragment derived from pMFG was inserted into the Hind III-Xho I sites of pdLMg1031, replacing the original Hind III-Xho I portion, generating pdLInMg1031. $\mathrm{pdL}(\mathrm{XX})$ and $\mathrm{pdL}(\mathrm{BB})$ were derived from pdLMg1031 by converting its Bam $\mathrm{HI}$ site to Xho I and the Xho I site to Bam HI. They were used to generate pdLiMg1031 (see text). LTR, Long terminal repeat; SD, splicing donor site; SA, splicing acceptor site; $\psi$, viral packaging signal; Me, MCK enhancer; intron, shortened first intron of hFIX gene in its natural position; I-VIII, exons of the FIX gene. Arrows show the sites and the direction of transcription. The X in the $3^{\prime}$ LTR indicates the deleted enhancer region. Relevant restriction sites are shown with short vertical bars. The constructs shown are inserted in the pBR322 vector at the Hind III and Eco RI sites. 
$\mathrm{pdL}$ vector frame was derived from pdLMe $2 \beta \mathrm{A} 280 \mathrm{hIX}$ (Yao et al., 1994) by deleting its Me2 $\beta A 280 \mathrm{hIX}$ portion with Xho $\mathrm{I} /$ Bam $\mathrm{HI}$ digestion. This vector has its $\mathrm{U} 3$ enhancer region (178 bp) in the 3' LTR deleted (Wilson et al., 1988). pdLMe2$\beta A 280 \mathrm{hlXm} 1$ was constructed by replacing the hFIX cDNA in pdLMe $2 \beta A 280 \mathrm{hIX}$ with a hFIX minigene, hIXm1, which contains the first intron sequence of the hFIX gene with its middle 4.8-kb sequence truncated out of the original $6.2 \mathrm{~kb}$ (Kurachi et al., 1995). The Mg1031 fragment prepared as described above was inserted into the pdL vector frame, thus generating pdLMg1031 (Fig. 1B). hIXm1 was then inserted into this intermediate vector at the unique Bam HI site, generating pdLMg1031hIXm1. Four copies of Me (Me4) were then inserted into this vector at the Xho I site, producing pdLMe4Mg1031hIXml. The Mg1031 promoter sequence in these vectors was then replaced by various other promoter sequences $(\mathrm{Mg} 353, \beta \mathrm{A} 280)$, thus generating a series of pdL-type vectors.

pdLIn vector frame was derived from plasmid pdLMg1031 and pMFG (Dranoff et al., 1993) (Fig. 1B). pMFG contained an intron sequence (In) in the retroviral vector frame that was derived from the splicing donor sequence (SD) located $5^{\prime}$ to the packaging sequence region $(\psi)$, and a splicing acceptor sequence (SA) derived from the envelope gene sequence. A unique Bam $\mathrm{HI}$ site located downstream of the viral intron sequence of PMFG was converted to an $X h o$ I site by ligating an $X$ ho I linker. The plasmid DNA was then cleaved with Xho I and Hind III (Fig. 1B), generating a 2.2-kb Hind III-Xho I fragment containing the $5^{\prime}$ LTR, packaging signal sequence, and complete splicing sequence. This fragment was then inserted into pdLMg1031 at Hind III/Xho I sites, replacing the corresponding Hind III-Xho I fragment $(2.4 \mathrm{~kb})$, thus generating pdLInMg1031. hIXm1 and Me (1, 2, and 4 copies) were then inserted into these vectors at the unique Bam $\mathrm{HI}$ and $\mathrm{Xho}$ I sites in a similar manner as described for pdL vectors, generating the pdLIn vectors with $\mathrm{Mg} 1031$ and $\mathrm{hLXm} 1$. The Mg1031 promoter sequence was then replaced with various other promoter sequences (Mg353, $\beta$ A280, CO1250, CO650, and RSV), thus resulting in a series of pdLIn-type vectors.

The pdLi vector frame, which contains an internal hFIX expression unit in an inverted orientation relative to the $5^{\prime}$ LTR, was derived from the pdL vector frame. The unique $X h o I$ and Bam HI sites in the pdL vector frame were converted to Bam $\mathrm{HI}$ and $\mathrm{Xho} \mathrm{I}$, respectively. The resulting two intermediate constructs, pdL(BB) and pdL(XX), which have a unique Bam $\mathrm{HI}$ or Xho I site, respectively (Fig. 1B), were then digested with a combination of Hind III and Bam HI or Hind III and Xho I, generating a $2.4-\mathrm{kb}$ Hind III-Bam HI fragment containing 5' LTR, SD, and $\psi$ signal of pdL, or 5.6-kb Xho I-Hind III fragment containing $3^{\prime}$ LTR and pBR322 backbone sequence. These two fragments and $\mathrm{Mg} 1031$ fragment with Xho I/Bam HI ends were ligated, thus producing pdLiMg1031 with its $\mathrm{Mg} 1031$ sequence in an inverted orientation relative to the $5^{\prime}$ LTR. A Bam HI-Bgl II fragment $(0.38 \mathrm{~kb})$ containing the $3^{\prime}$ untranslated region of the hFIX gene with its poly(A) signal sequence was prepared from a hFIX expression vector, p-416hIXm1 (Kurachi et al., 1995). This fragment was inserted into pdLiMg1031 at the Bam HI site in the same direction as the Mg1031 promoter, generating pdLi(pA)Mg1031. hIXm1 and $\mathrm{Me} 2$ or Me4 were then inserted into the vectors at Bam HI and Xho I sites, respectively, generating pdLihIXmlMg1031, pdLihIXm1Mg1031Me2, and pdLihIXm1Mg1031Me4. $\mathrm{Mg} 1031$ in these vectors was then replaced by various other promoters (Mg353, $\beta \mathrm{A} 280, \beta \mathrm{A} 200, \alpha \mathrm{A} 775$, and CO650), and $\mathrm{h}[\mathrm{Xml}$ in some constructs was replaced with hIXm2, another $\mathrm{hFIX}$ minigene, thus generating a series of pdLi-type vectors (Table 2). hIXm2 was derived from hIXml by further shortening the intron sequence by $1.1 \mathrm{~kb}$ leaving only a $0.3 \mathrm{~kb}$ intron sequence of the hFIX gene (Kurachi et al., 1995).

All PCR-derived DNA fragments and ligation sites of the essential components in the newly constructed vectors were sequenced to confirm their correct structures. The vector plasmid DNAs used for transfection experiments were purified using a Qiagen plasmid kit or two cycles of ultracentrifugation banding through $\mathrm{CsCl}$ gradient.

\section{Cells and culture conditions}

Primary skeletal myoblasts were isolated from SCID mouse hind leg muscles as previously described (Yao and Kurachi, 1993) and used in the present expression assays. Cells were grown in Dulbecco's modified essential medium (DMEM) (GIBCO/BRL) supplemented with $20 \%$ fetal calf serum (FCS), $0.5 \%$ chicken embryo extract (CEE) (GIBCO/BRL), and streptomycin and penicillin. All cell culture dishes were kept at $37^{\circ} \mathrm{C}$ in humidified incubators with $5 \% \mathrm{CO}_{2}$.

\section{Enzyme-linked immunosorbent assay of $h F I X$}

hFIX produced was quantified by hFIX-specific enzymelinked immunosorbent assay (ELISA) using a murine anti-hFIX monoclonal antibody (AHIX-5041, Haematologic Technologies Inc.) as the catching antibody and rabbit polyclonal anti-hFIX as the detecting antibody (Yao et al., 1991; Kurachi et al., 1995). A microtiter plate reader (Bio-Tek model EL312e) was used for quantitation. This ELISA detected neither bovine nor murine factor IX at any significant level, permitting a precise determination of hFIX produced at sub-nanogram levels in the culture medium.

\section{Transient expression of hFIX in culture}

For assaying the transient expression activities of the vectors, LIPOFECTAMINE-mediated cell transfection was used according to the manufacturer's instruction (GIBCO/BRL). Twenty-four hours prior to transfection, primary myoblasts were plated at a density of $2 \times 10^{5} /$ well in six-well cell culture plates (Coming). Expression vector DNA $(2 \mu \mathrm{g})$ and pCH1 10 DNA ( $\beta$-Gal expression vector, $0.2 \mu \mathrm{g}$ ) (Herbomel et al., 1984) were mixed with LIPOFECTAMINE $(30 \mu \mathrm{g})$ in Opti-MEM (GIBCO/BRL; total volume $100 \mu \mathrm{l}$ ) and incubated at room temperature for $15 \mathrm{~min}$. Aliquots of Opti-MEM $(900 \mu \mathrm{l})$ were then added and the DNA-LIPOFECTAMINE complexes formed were added to each well with cells, which were in advance rinsed once with Opti-MEM. Cells were then incubated at $37^{\circ} \mathrm{C}$ under $5 \% \mathrm{CO}_{2}$ for $6 \mathrm{hr}$, followed by addition of $1-\mathrm{ml}$ aliquots of the myoblast culture medium. Twenty hours later, the DNA-LIPOFECTAMINE transfection medium was removed, and the cells were washed twice with phosphate-buffered saline. Two milliliters of hFIX assay medium (DMEM, $20 \% \mathrm{BaSO}_{4-}$ treated FCS, $10 \mu \mathrm{g} / \mathrm{ml}$ Vitamin $\mathrm{K} 1$, and $0.5 \%$ CEE) were then 
TABle 2. Human Factor IX Expression Vectors

\begin{tabular}{|c|c|c|c|c|c|c|}
\hline $\begin{array}{l}\text { Vector } \\
\text { Type* }\end{array}$ & & Vector Name & $\begin{array}{c}\text { Promoter } \\
\text { (Size in bp) }\end{array}$ & $\begin{array}{c}\text { Me } \\
\text { (Copy No.) }\end{array}$ & $\begin{array}{l}\text { hFIX } \\
\text { Gene }\end{array}$ & $\frac{\text { hFIX }}{(n g / m l)^{\star \star}}$ \\
\hline \multirow[t]{7}{*}{ pdL } & 1 & pdLMg103 IhIXml & Murine Myogenin (1031) & 0 & $\mathrm{~m} 1$ & $16.6 \pm 2.3$ \\
\hline & 2 & pdLMe4Mg103 lhIXm l & Murine Myogenin (1031) & 4 & $\mathrm{ml}$ & $78.4 \pm 7.9$ \\
\hline & 3 & pdLMg353hIXml & Murine Myogenin (353) & 0 & $\mathrm{ml}$ & $25.5 \pm 4.4$ \\
\hline & 4 & pdLMe4Mg353hlXm1 & Murine Myogenin (353) & 4 & $\mathrm{ml}$ & $98.9 \pm 11.5$ \\
\hline & 5 & pdLMe $2 \beta A 280 \mathrm{hIX}$ & Chicken $\beta$-Actin (280) & 2 & cDNA & $5.3 \pm 2.3$ \\
\hline & 6 & pdLMe $2 \beta A 280 \mathrm{hlXm} 1$ & Chicken $\beta$-Actin (280) & 2 & $\mathrm{ml}$ & $126.7 \pm 10.7$ \\
\hline & 7 & pdLMe $4 \beta A 280 \mathrm{hIXml}$ & Chicken $\beta$-Actin (280) & 4 & $\mathrm{ml}$ & $161.4 \pm 16.1$ \\
\hline \multirow[t]{14}{*}{ pdLIn } & 8 & pdLInMg103lhlX & Murine Myogenin (1031) & 0 & cDNA & $1.5 \pm 0.5$ \\
\hline & 9 & pdLInMg1031hIXm1 & Murine Myogenin (1031) & 0 & $\mathrm{ml}$ & $21.0 \pm 7.1$ \\
\hline & 10 & pdLInMe1Mg $1031 \mathrm{hIXml}$ & Murine Myogenin (1031) & 1 & $\mathrm{ml}$ & $40.6 \pm 2.7$ \\
\hline & 11 & pdLInMe2Mg1031hIXm1 & Murine Myogenin (1031) & 2 & $\mathrm{ml}$ & $71.8 \pm 11.2$ \\
\hline & 12 & pdLInMe $4 \mathrm{Mg} 1031 \mathrm{hIXm} 1$ & Murine Myogenin (1031) & 4 & $\mathrm{ml}$ & $87.1 \pm 8.8$ \\
\hline & 13 & pdLInMg353hIXm l & Murine Myogenin (353) & 0 & $\mathrm{ml}$ & $33.1 \pm 6.2$ \\
\hline & 14 & pdLInMe4Mg353hIXml & Murine Myogenin (353) & 4 & $\mathrm{ml}$ & $106.2 \pm 12.6$ \\
\hline & 15 & pdLIn $\beta A 280 \mathrm{hIXml}$ & Chicken $\beta$-Actin (280) & 0 & $\mathrm{ml}$ & $54.2 \pm 3.4$ \\
\hline & 16 & pdLInMe $\beta A 280 \mathrm{hIXm} \mathrm{I}$ & Chicken $\beta$-Actin (280) & 4 & $\mathrm{ml}$ & $160.7 \pm 13.2$ \\
\hline & 17 & pdLInCO650hIXm1 & Calf Cyto Oxidase (650) & 0 & $\mathrm{ml}$ & $53.9 \pm 9.7$ \\
\hline & 18 & pdLInMe4CO650hIXm1 & Calf Cyto Oxidase (650) & 4 & $\mathrm{ml}$ & $81.6 \pm 8.0$ \\
\hline & 19 & pdLInCO1250hIXm1 & Calf Cyto Oxidase (1250) & 0 & $\mathrm{ml}$ & $8.8 \pm 3.4$ \\
\hline & 20 & pdLInRSVhIXm 1 & Rous Sarcoma Virus & 0 & $\mathrm{ml}$ & $49.2 \pm 5.6$ \\
\hline & 21 & pdLlnMe 4 RSVhlXm l & Rous Sarcoma Virus & 4 & $\mathrm{ml}$ & $86.6 \pm 7.9$ \\
\hline \multirow[t]{12}{*}{$\mathrm{pdLi}$} & 22 & pdLihlXm1Mgl031 & Murine Myogenin (1031) & 0 & $\mathrm{~m} 1$ & $4.4 \pm 0.6$ \\
\hline & 23 & pdLihIXm1Mg1031Me2 & Murine Myogenin (1031) & 2 & $\mathrm{ml}$ & $46.4 \pm 2.1$ \\
\hline & 24 & pdLihIXmlMg1031Me4 & Murine Myogenin (1031) & 4 & $\mathrm{ml}$ & $85.9 \pm 12.4$ \\
\hline & 25 & pdLihIXm1Mg353Me4 & Murine Myogenin (353) & 4 & $\mathrm{ml}$ & $118.5 \pm 14.6$ \\
\hline & 26 & pdLihIXm2Mg353Me4 & Murine Myogenin (353) & 4 & $\mathrm{~m} 2$ & $91.3 \pm 12.8$ \\
\hline & 27 & pdLihIXm1ßA280Me4 & Chicken $\beta$-Actin (280) & 4 & $\mathrm{ml}$ & $153.5 \pm 16.8$ \\
\hline & 28 & pdLihIXm2 $2 \beta A 280 \mathrm{Me} 4$ & Chicken $\beta$-Actin (280) & 4 & $\mathrm{~m} 2$ & $146.9 \pm 16.4$ \\
\hline & 29 & pdLihIXm $1 \beta A 200$ & Chicken $\beta$-Actin (200) & 0 & $\mathrm{ml}$ & $30.7 \pm 4.0$ \\
\hline & 30 & pdLihIXm2 $2 \beta A 200$ & Chicken $\beta$-Actin (200) & 0 & $\mathrm{~m} 2$ & $28.3 \pm 3.1$ \\
\hline & 31 & pdLihlXm $2 \beta$ A200Me4 & Chicken $\beta$-Actin (200) & 4 & $\mathrm{~m} 2$ & $141.5 \pm 5.9$ \\
\hline & 32 & pdLihlXmlCO650Me4 & Calf Cyto Oxidase (650) & 4 & $\mathrm{ml}$ & $44.4 \pm 5.1$ \\
\hline & 33 & pdLihIXml $\propto$ A775Me4 & Human $\alpha$-actin (775) & 4 & $\mathrm{~m} 1$ & $80.3 \pm 8.6$ \\
\hline LIXSN & 34 & LIXSN & MoMLV LTR & 0 & cDNA & $10.2 \pm 0.7$ \\
\hline
\end{tabular}

*pdL, Retroviral vector frame with its 3' LTR enhancer region (178 bp) deleted; pdLIn, vector frame with a splicing unit derived from the MFG vector and the $3^{\prime}$ LTR enhancer region deleted as in pdL; pdLi, vector frame with the same vector backbone as pdL, except the inverted orientation of the internal hFIX expression unit in relation to $5^{\prime} \mathrm{LTR}$.

${ }^{* *} \mathrm{hFIX}$ produced into the culture medium of myotubes on day 7 shown in $\mathrm{ng} / \mathrm{ml}$, which is equivalent to those in $\mathrm{ng} / 10^{6} \mathrm{cells} / 24$ hr. Average hFIX production levels with SD ( $n=4-6$ from two to four independent experiments) are shown. The expression levels of different vectors were normalized to the level of one to two vectors commonly tested in different sets of experiments.

added. The medium was collected every $24 \mathrm{hr}$ and the same volume of fresh medium was added. After $48 \mathrm{hr}$, myoblast differentiation medium containing $2 \% \mathrm{BaSO}_{4}$-treated horse serum (HS) was added to two out of four wells for each construct. This was replaced with fresh medium every $24 \mathrm{hr}$ up to day 6 to induce myoblast differentiation into myotubes. Cell numbers at the time of switching to the differentiation medium was about $2 \times 10 \%$ well at $80-90 \%$ confluency. Under these conditions, differentiation was completed in 2.5-3 days. At the end of day
6 , the medium was replaced with the hFIX assay medium and incubated for additional $24 \mathrm{hr}$. Amounts of hFIX protein produced into the medium were quantified by ELISA and normalized to the $\beta$-Gal activity (internal control for transfection efficiency). Myoblast cell numbers, $\beta$-Gal activities, and total cellular protein amounts were determined using the remaining two wells at the end of day 2. $\beta$-Gal activity was determined according to Eustice et al. (1991) with minor modifications. The total protein concentration of cell extracts was measured 
by the Bio-Rad protein assay kit (Bio-Rad Laboratories) according to the manufacturer's instruction.

pLIXSN and pdLMe2 $\beta$ AhIX, which we previously reported (Yao et al., 1991, 1994), were used as reference expression vectors in assaying the newly constructed vectors for their transient expression activities.

\section{Northern blot analysis of muscle cells transfected with hFIX expression vectors}

Polyadenylated RNAs were prepared using the QuickPrep Micro mRNA purification kit (Pharmacia Biotech) from cells on day 2 (myoblasts) and day 5 (myotubes) after transfection, and subjected to Northern blot analysis as previously described (Kurachi et al., 1995). hFLX cDNA labeled with ${ }^{32} \mathrm{P}$ to a specific activity of $\sim 1 \times 10^{9} \mathrm{cpm} / \mu \mathrm{g}$ was used as the hybridization probe for blotted filter membranes. After stripping off the $\mathrm{hFIX}$ probe, the membrane was rehybridized with the ${ }^{32} \mathrm{P}$-labeled human $18 \mathrm{~S}$ ribosome RNA cDNA (American Type Culture Collection) as controls for equal loading of mRNA samples. RNA levels were quantified by a PhosphorImager (Molecular Dynamics) and hFIX mRNA levels were normalized to those observed for $18 \mathrm{~S}$ ribosome RNA.

\section{RESULTS}

\section{Construction of hFIX expression vectors and their expression activities}

hFIX expression vectors and transient expression activities assayed with myotubes are summarized in Table 2 . All the vectors contained an internal hFIX expression cassette inserted in one of the three MoMLV-derived vector frames (Fig. 1A). Internal $\mathrm{hFIX}$ expression cassettes consisted of various combinations of a promoter (either muscle-specific, viral, or housekeeping gene promoters), muscle creatine kinase enhancer (Me) in different copy numbers, and a hFIX minigene in two different forms. Promoters tested included those of $\beta A$ in two lengths ( $\beta$ A280 and $\beta$ A200, the latter with all potential polyadenylation sites in the complementary strand eliminated), $\mathrm{Mg}$ with two different lengths (Mg1031 and Mg353), muscle-specific CO with two different lengths (CO1250 and CO650), RSV, and $\alpha \mathrm{A}$ $(\alpha \mathrm{A} 775)$. hFIX sequences used were cDNA $(1.4 \mathrm{~kb})$ and two minigenes, $\mathrm{hIXm} 1$ (2.9 kg in length) and $\mathrm{hIXm} 2(1.7 \mathrm{~kb})$, containing truncated first-intron sequences. These vectors were systematically tested in a transient expression assay system with skeletal myoblasts and thereof derived myotubes to determine the relationship between various structural components and hFIX expression activity. Efficiency of myoblast transfection with LIPOFECTAMINE in the present study was approximately $20 \%$.

\section{Effects of minigenes}

As shown in Fig. 2, pdLInMg1031hIXm1 showed 10- to 14fold higher expression level in myotubes over that of pdLInMg1031hIX, indicating gross elevations in hFIX expression in the presence of hIXml over that with hFIX cDNA. Similar elevation due to the use of $\mathrm{hIXm} 1$ was also observed with $\beta$ A280 promoter (Table 2 ). The expression activity of

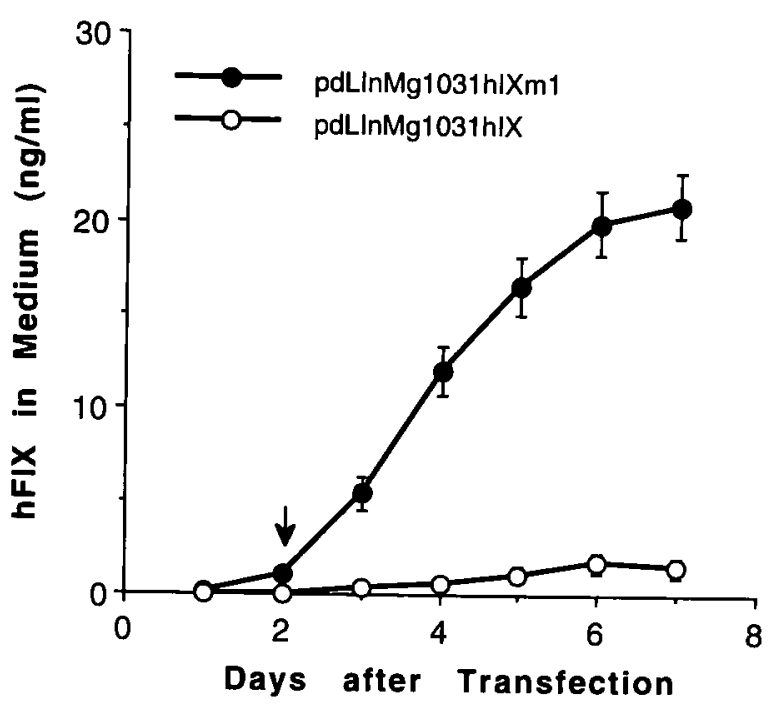

FIG. 2. Transient expression of hFIX by pdLInMg$1031 \mathrm{hIXml}(0)$ and pdLInMg1031 hIX (O) from skeletal muscle cells. Details of experimental conditions are described in Materials and Methods. Murine myoblasts $\left(2 \times 10^{5} /\right.$ well) were plated in a six-well plate 1 day prior to transfection. Cells were transfected with hFIX expression vector DNAs and pCH110 plasmid DNA (internal transfection efficiency control) using lipofectamine-mediated transfection. Twenty hours later, the transfection medium was replaced with $2 \mathrm{ml}$ of fresh complete growth medium (day 1). The medium was collected for ELISA every $24 \mathrm{hr}$ and was replaced with the fresh medium. Differentiation medium with $2 \%$ horse serum was added to cells beginning on day 3 through day 6 . Then the fresh growth medium was added to the cells for an additional $24 \mathrm{hr}$. Cell number at the beginning of differentiation was about $2 \times$ $10^{6} /$ well. Expression levels shown in $\mathrm{ng} / \mathrm{ml}$ are equivalent to those in $\mathrm{ng} / 1 \times 10^{6}$ cells per $24 \mathrm{hr}$. Vertical bars indicate standard deviations $(n=4)$. Arrow indicates the time point of switching to the differentiation medium.

hIXm2 was only slightly lower than that of $h I X m 1$, as shown by comparison between pdLihIXm1Mg353Me4 and pdLihIXm2Mg353Me4, pdLihIXm1 $\beta$ A280Me4 and pdLihLXm2$\beta A 280 \mathrm{Me} 4$, or pdLihIXm1 $\beta$ A200 and pdLihIXm $2 \beta A 200$ (Table 2). These results were in accord with our previous observations with the hFIX promoter (Kurachi et al., 1995). Therefore, hFIX minigenes were included in the newly constructed hFIX expression vectors in this study.

\section{Effects of different vector frames}

Three different retroviral vector frames, pdL, pdLIn, and pdLi, designed in the present study, permitted us to test several critical aspects of the basic structures of FIX expression vectors.

pdLIn vectors without $\mathrm{Me}$ (pdLInMg353hIXml and pdLInMg1031hIXml) showed only marginally $(20-30 \%, p=$ 0.052 ) higher expression activities than $\mathrm{pdL}$ vectors (pdLMg$353 \mathrm{hIXml}$ and pdLMg1031hIXml) (Table 2), suggesting only a minor contribution, if any, of the MFG vector intron sequence with the 5' LTR promoter to the overall expression levels. As shown for pdLMe4Mg353hIXml and pdLInMe4Mg353$\mathrm{hIXml}$, as well as for pdLMe4Mg1031hIXm1 and pdLInMe4$\mathrm{Mg} 1031 \mathrm{hIXm1}$, presence of Me greatly reduced the difference, 


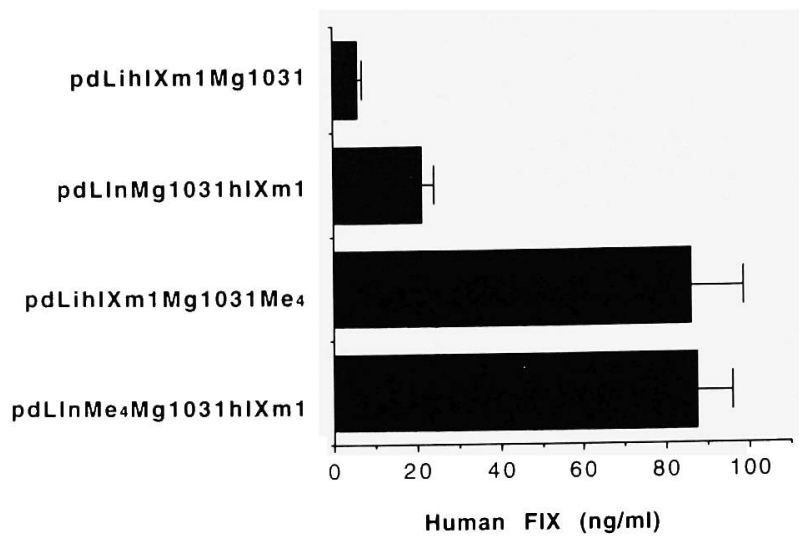

FIG. 3. Comparison of transient expression activities among the representative pdLIn and pdLi vectors with the Mg1031 promoter in the absence and presence of Me4. Experimental conditions are similar as described in Fig. 2. Transient expression activities of the vectors from myotubes were analyzed on day 7. Thin lines with vertical bars indicate standard deviations of three independent experiments.

and both pdL- and pdLIn-type vectors expressed hFIX equally well. Similarly, in the presence of Me, $\beta$ A2 280 could drive hFIX expression equally well for both pdL and pdLIn-type vectors.

pdLi vectors were designed to test the hFIX expression unit in the inverted orientation. Such vector structure was considered to be important in avoiding splicing of the intron sequence contained in the hFIX minigenes during retroviral RNA genome production in the packaging cells (Cone et al., 1987; Miller et al., 1988). pdLihLXm1Mg1031, which contained no Me, showed only $27 \%$ and $21 \%$ expression levels of those of pdLMg1031hIXm1 and pdLInMg1031hIXm1, respectively. In the presence of Me, however, pdLihIXm1Mg1031Me4 expressed hFIX at the levels equivalent to the counterpart constructs of pdL and pdLIn-type vectors, pdLMe4Mg1031hIXm1 and pdLInMe4Mg1031hIXml (Fig. 3, Table 2).

\section{Effects of MCK enhancers}

As typically shown for a series of pdLInMg1031hIXm1 vectors with one, two, and four copies of Me (vectors 10-13 in Table 2), the overall hFIX expression level was elevated 2.0-, 3.7-, and 4.5-fold over that with no Me (pdLInMg1031hIXml) (Fig. 4). The first one and two copies of Me gave the most drastic increases in expression, while the additional two copies present in Me4 gave less enhancing effects per Me copy. pdLInMg353hIXm1 series vectors, which contained the short $\mathrm{Mg}$ promoter also showed similar enhancements with increasing number of Me copy (Table 2). Similar general effects of Me were also observed with both pdL- and pdLi-type vectors. Among the three types of vectors, however, enhancing effects of Me were most dramatic with pdLi-type vectors as typically shown for pdLihIXm1Mg1031 series of vectors (Table 2, Fig. 5). In comparison to pdLihIXm1Mg1031, which expressed 4.4 $\mathrm{ng} / \mathrm{ml}$ of hFIX on day 7, vectors with two and four Me copies (pdLihIXm1Mg1031Me2 and pdLihIXm1Mg1031Me4, respectively) expressed 46.4 and $85.9 \mathrm{ng} / \mathrm{ml}$ (10- and 19.5-fold enhancements), respectively (Fig. 5). The substantial differences in the enhancement rate between pdLi and the other two vector types (pdL and pdLIn) are due to the lower basal activity of pdLi vectors in the absence of Me than those of $\mathrm{pdL}$ and pdLIn vectors (Table 2). As mentioned above, the hFIX expression levels of $\mathrm{pdLi}, \mathrm{pdL}$, and pdLIn vectors with four Me copies (Me4) are not significantly different.

\section{Effects of different promoters}

Different promoters tested in the hFIX expression vectors showed substantially varied hFIX expression activities and muscle cell specificity. Vectors with Mg1031 promoter showed marked preference for myotubes, as expected, from the previous report (Edmondson et al., 1992) (Figs. 2 and 6). When the culture medium was switched to the differentiation medium on day 2 (end of $48 \mathrm{hr}$ after transfection), hFIX expression of pdLInMg1031hIXm1 rose from $1.6 \mathrm{ng} / \mathrm{ml}$ medium with myoblasts to $21.0 \mathrm{ng} / \mathrm{ml}$ on day 7 with myotubes, a 13.1-fold increase (Fig. 6). This large increase was not due to a modest increase in myoblast cell number $(<20 \%$ at most) observed after switching the medium to a differentiation medium. The observed myotube-specific increase in expression was also observed with the short form of myogenin promoter $(\mathrm{Mg} 353)$. pdLInMg $353 \mathrm{hIXm} 1$ expressed $33.1 \mathrm{ng} / \mathrm{ml}$ on day 7, a 13.2-fold increase over that on day $2(2.5 \mathrm{ng} / \mathrm{ml}$ medium $)$. Vectors with Mg353 showed about 20-60\% higher expression levels than with $\operatorname{Mg} 1031(p=0.010)$ (Figs. 6 and 7). On day 7, pdLInMg1031hIXm1 expressed $21.0 \mathrm{ng} / \mathrm{ml}$ medium of hFIX (average of four independent experiments), whereas the pdLInMg353hiXm1 expressed $33.1 \mathrm{ng} / \mathrm{ml}$ medium (Table 2). Higher expression levels were also observed for $\mathrm{Mg} 353$ over $\mathrm{Mg} 1031$ in the presence of $\mathrm{Me}$, regardless of different vector frames (pdL or pdLi).

CO650 and CO1250 showed similar differentiated muscle cell-specific expression (data not shown). CO650 also had a significantly higher basal activity than CO1250. pdLInCO650hIXm1 expressed $53.9 \mathrm{ng} / \mathrm{ml}$ medium of hFIX (average of three independent assays), whereas pdLInCO1250hIXml gave only $8.8 \mathrm{ng} / \mathrm{ml}$ (Table 2).

$\mathrm{CO650,} \mathrm{RSV}$, and $\beta \mathrm{A} 280$ promoters had similar basal promoter activities, which were substantially higher than those of

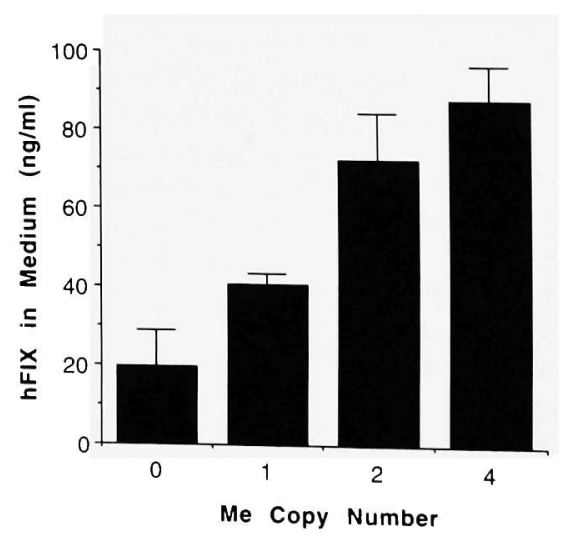

FIG. 4. Effects of increasing copy numbers of MCK enhancer (Me) on transient expression of hFIX by pdLInMg1031IXml. Averages of hFIX amounts produced from myotubes (day 7) in two experiments are shown with the observed expression ranges
(vertical bars). 


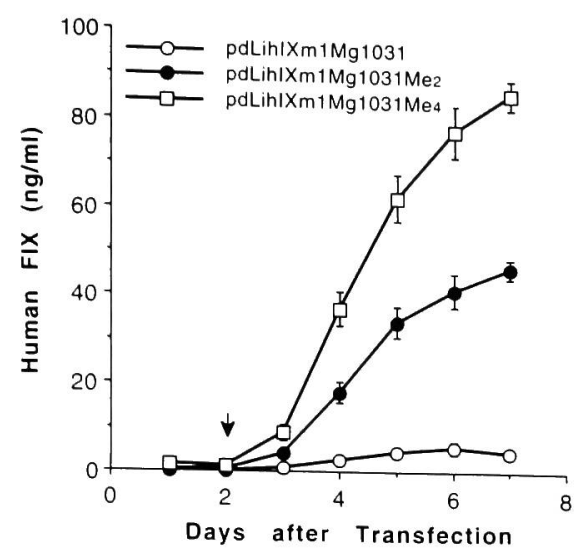

FIG. 5. Expression of hFIX in myoblasts and myotubes by pdLi vectors with $\mathrm{Mg} 1031$ promoter and MCK enhancer (none, two, and four). Expression conditions were similar to those described in Fig. 2. (O) pdLihIXmlMg1031; (O) pdLhIXm1Mg1031Me2; ( $\square$ ) pdLihIXm1Mg1031Me4. Arrow indicates the medium switch for cell differentiation. Vertical bars are standard deviations of triplicated assays.

$\mathrm{Mg} 1031$ and $\mathrm{Mg} 353$ (Table 2, Fig. 7a). In the presence of Me4, however, $\mathrm{Mg} 353$ gave a $30 \%$ and $23 \%$ higher activities than those of CO650 and RSV, whereas $\beta$ A280 gave the highest activity level of all vectors tested, which was $51 \%$ higher than that of $\mathrm{Mg} 353$.

Regardless of the vector frames used, $\beta \mathrm{A}$ promoter with $\mathrm{Me}$ consistently showed the highest expression activity in myotubes among the promoters tested. Me4 could enhance the activity of RSV and CO650 in pdLIn vectors by 1.5 - and 1.8 -fold, respectively, over those without Me. The enhanced expression levels of these vectors, however, were equivalent to the level only half of that of $\beta \mathrm{A}$ construct (pdLInMe4 $\beta \mathrm{A} 280 \mathrm{hIXm1}$ ) (Fig. 7A). $\alpha \mathrm{A} 775$, another differentiated muscle cell specific promoter, gave a promoter activity similar to that of Mg1031

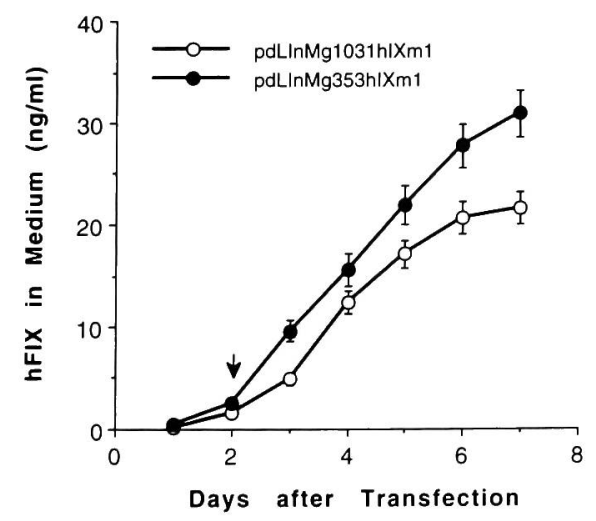

FIG. 6. hFIX expression activities of myogenin promoters $\mathrm{Mg} 1031$ and $\mathrm{Mg} 353$ in skeletal muscle cells. Assay conditions were similar to those in Fig. 2. The results from two constructs, pdLInMg1031hIXm1 (O) and pdLInMg353hIXm1 (O) are shown. The arrow indicates medium switch for cell differentiation. Results of a set of representative experiment with four duplicates are shown with standard deviations (vertical bars).

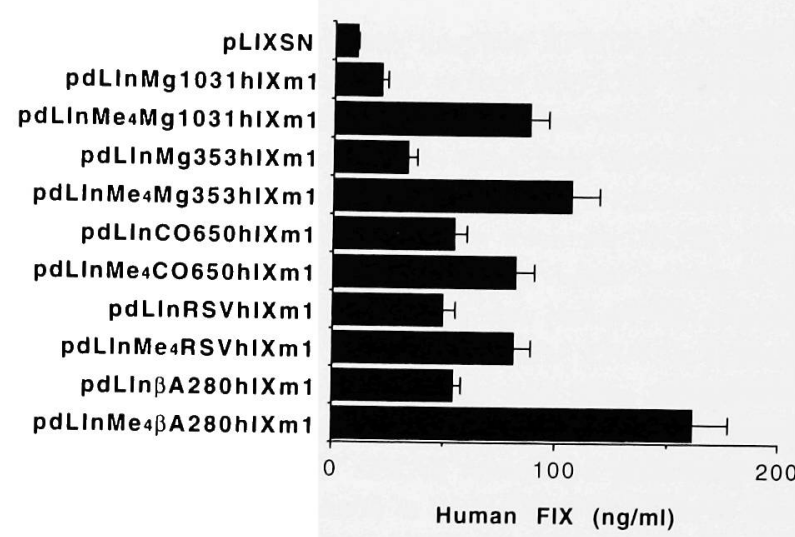

A

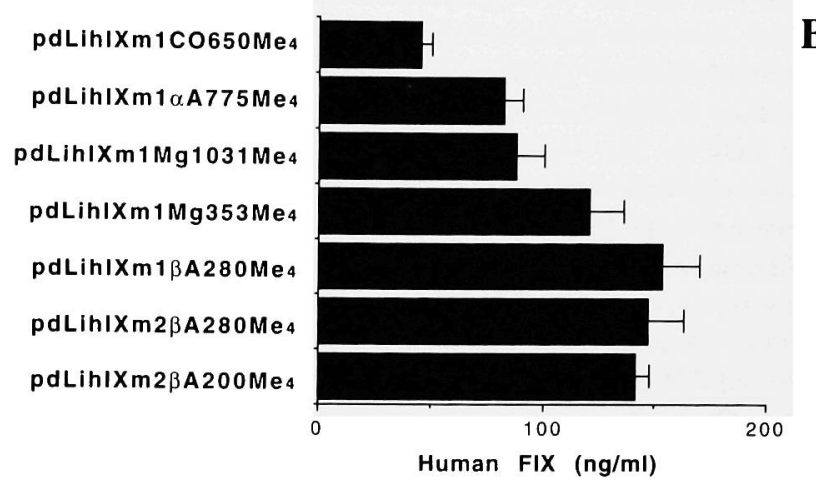

FIG. 7. Comparison of hFIX expression activities by vectors with different promoters with or without Me4. Experimental conditions were similar to those in Fig. 2. A. pdLIn vectors with or without Me4. pLIXSN is included as a reference vector. Thin lines with vertical bars indicate standard deviations of four duplicated assays. Results shown are from the day 7 data of a representative experiment. B. pdLi vectors with Me4. hFIX expressed on day 7 of two experiments is shown with the observed ranges.

as shown for pdLihIXm1 $\alpha$ A775Me4 and pdLihIXm1Mg$1031 \mathrm{Me} 4$ (Fig. 7B).

The order of the promoter strength in pdL-type and pdLIntype vectors with Me4 was determined with myotubes as, $\beta \mathrm{A} 280>\mathrm{Mg} 353>\mathrm{Mg} 1031 \approx \mathrm{RSV} \approx \mathrm{CO} 650>\mathrm{CO} 1250$ (Fig. 7A, Table 2). Various promoters with Me4 in the pdLi frame also gave a similar order in their strength, except that CO650 activity was only 52\% of Mg1031. hFIX expression levels of pdLInMe $4 \beta A 280 \mathrm{hIXm} 1$ and pdLihIXm1 $\beta$ A $280 \mathrm{Me} 4$ in myotubes ( $160.7 \pm 12.6$ and $153.5 \pm 16.8 \mathrm{ng} / \mathrm{ml}$, respectively) were 15- to 16-fold and 30-fold higher than those of our previous vectors, $\mathrm{pLIXSN}$ and pdLMe $2 \beta \mathrm{AhIX}$, respectively (Yao et al., 1994). In the present transient assay system, the latter two vectors expressed $10.2 \pm 0.7$ and $5.3 \pm 2.3 \mathrm{ng} / \mathrm{ml}$ of hFIX, respectively (Table 2 ).

\section{Structure of highly refined expression vector}

On the basis of the results summarized above, the optimal basic structure of the hFIX expression vector to be used for production of hFIX by muscle-targeted gene transfer should contain $\beta \mathrm{A}$ promoter, Me 2 or Me4, and the hFIX minigene. Among the three vector frames used, only the pdLi-type frame should be able to prevent a loss of the expression-augmenting effects 
of the intron of hFIX minigene due to its splicing in the packaging cells. pdLi-type vectors with Me4 expressed hFIX at the levels equivalent to the counterpart $\mathrm{pdL}$ and $\mathrm{pdLIn}$ vectors, indicating that the basic pdLi vector structure functions well.

To construct a further refined vector with the pdLi vector frame, $\beta$ A280 promoter was modified by truncating its $5^{\prime} 80$ bp sequence, where two potential polyadenylation signal sequences (AATAAA) were present in the complementary strand (Kost et al., 1993; Miller et al., 1988). In addition, several base substitutions were also made to the remaining promoter sequence to eliminate all other potential polyadenylation sites, thus generating a promoter $\beta$ A200. These modifications were done to eliminate possibilities of premature polyadenylation of the viral genome RNA produced in the packaging cells. All of the removed or modified regions contain no known specific enhancer elements. $\beta$ A200 still retained a promoter activity very similar to $\beta A 280$ as shown with both hIXm1 and hIXm2 (Table 2 and Fig. 7B). Because hIXm2 was also devoid of potential polyadenylation sites in the complementary strands, which are present in the hIXm1 in its intron sequence region, we utilized $\mathrm{hLXm} 2$ in a highly optimized vector system with the pdLi vector frame. pdLihLXm2 $\beta$ A200Me4 expressed hFIX at a level of $146.9 \mathrm{ng} / \mathrm{ml}$ medium from myotubes, an equivalent level of that of pdLihLXm1 $\beta$ A280Me4, indicating no significant detrimental effects of these modifications of the $\beta A$ promoter and the hFIX minigene (Fig. 7B).

\section{Northern blot analysis of muscle cells transfected with hFIX expression vectors}

As shown in Fig. 8, pdLMe $4 \beta A 280 \mathrm{hIXm} 1$, pdLInMe $4 \beta A$ 280hLXm1, pdLihIXm1 $\beta$ A280Me4, and pdLihIXm2 $\beta A$ $200 \mathrm{Me} 4$ produced approximately equal amounts of the major hFIX mRNA bands $(\sim 1.9 \mathrm{~kb}$ in lanes 7 and $8 ; \sim 1.6 \mathrm{~kb}$ in lanes 5 and 6 ), which were produced by the internal promoter, in myotubes on day 5 (third day after the initiation of differentiation). In myotubes, pdLihIXm2 $\beta$ A200Me4 (lane 5) and pdLihIXm1$\beta \mathrm{A} 280 \mathrm{Me} 4$ (lane 6 ) produced approximately four- to five-fold more mRNA than pdLihLXm1 $\beta$ A200 (lane 4). pdLihIXm1 $\beta$ A280Me4 produced a significantly less amount of mRNA in myoblasts (day 2) (lanes 2) in comparison to that in myotubes (day 5) (lanes 6). These are consistent with the relative hFIX expression levels of these vectors observed in myotubes and myoblasts. Interestingly, pdLihIXm1 $\beta$ A200 also consistently gave a higher hFIX mRNA level in myotubes on day 5 than in myoblasts on day 2 .

\section{DISCUSSION}

Skeletal muscle cells can be relatively easily targeted for in vivo and ex vivo gene transfers and their great potential to serve as an efficient and safe medium for producing various recombinant proteins has been demonstrated (Barr and Leiden, 1991; Dai et al., 1992; Yao and Kurachi, 1992; Bansal et al., 1994; Baque et al., 1994; Hamamori et al., 1995). To establish a durable muscle-targeted gene therapy, however, development of a highly refined gene expression vector system has become one of the most critical issues. In the present study, we constructed a series of new hFIX expression vectors in three dif-
A

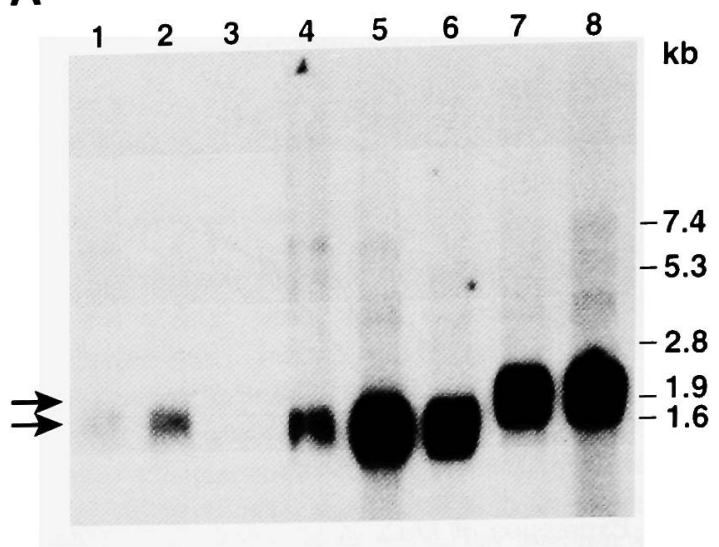

B

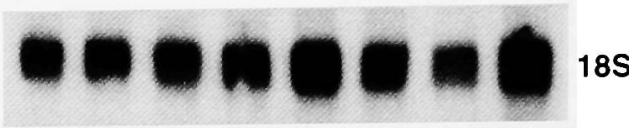

FIG. 8. Northern blot analysis of muscle cells transfected with hFIX expression vectors. A. Lanes 1 and 2 contain poly (A) ${ }^{+}$RNA samples prepared from the myoblasts on day 2 post transfection with pdLihIXm1 $\beta$ A200 and pdLihLXm$1 \beta \mathrm{A} 280 \mathrm{Me} 4$, respectively. Lanes $4-8$ contain poly(A) ${ }^{+} \mathrm{RNA}$ samples prepared from the myotubes derived from myoblasts on day 5 post transfection with pdLihIXm1 $\beta$ A200, pdLihIXm$2 \beta A 200 \mathrm{Me} 4$, pdLihIXm1 $\beta$ A280Me 4 , pdLInMe4 $\beta$ A280hIX$\mathrm{m} 1$, and pdLMe $4 \beta \mathrm{A} 280 \mathrm{hIXm} 1$, respectively. Lane 3 contains poly $(A)^{+}$RNA prepared from the mock-transfected muscle cells. Numbers on the right side indicate RNA molecular weight marker. Arrows on the left side indicate the position of hFIX mRNA bands of $\sim 1.9 \mathrm{~kb}$ in lanes 7 and 8 and $\sim 1.6 \mathrm{~kb}$ in lanes $1,2,4,5$, and 6 , respectively. $\mathrm{B}$. The presence of approximately equivalent RNAs in all lanes is shown by the presence of $18 \mathrm{~S}$ ribosomal RNA. See the text for the experimental conditions.

ferent retroviral vector frames and systematically analyzed the relationship among vector structure, expression components, and hFIX expression activity.

\section{Effects of different vector frames}

Three basic retroviral vector frames, pdL, pdLIn, and pdLi (Fig. 1), provided us with an excellent model system to examine several critical issues in developing an optimal hFIX retroviral vector structure. These issues include: (i) how high an expression level can be achieved by improving pdL-type vectors; (ii) how much effect does the MFG-type viral intron sequence contained in pdLIn-type vectors have on the internal transcriptional control unit; (iii) what is the relative strength of the 5' LTR promoter in the different vector frames; (iv) what is the transcriptional activity level that can be achieved by the internal hFIX expression unit with pdLi in relation to pdL and pdLIn vectors; and (v) what is the basic vector frame to be included in an optimal hFIX retroviral vector.

pdL-type vectors, which are the simplest of the three vector frames tested in the present study, were previously used in human gene therapy of hypercholesterolemia (Grossman et al., 1994). After a series of testings with the hFIX minigene, different promoters and additional muscle-specific enhancers 
(Me), a specific combination of these components as represented in pdLMe4 $\beta A 280 \mathrm{hIXm1}$, gave the highest hFIX expression levels among the pdL vectors (Table 2).

The pdLIn-type vectors, which have a MFG-derived vector intron sequence, were of particular interest because of their potential for an elevated transgene expression. In recent years, the MFG retroviral vector has been reported for its capability to express transgenes at substantial levels in various cell types such as hematopoietic cells (Ohashi et al., 1992; Dranoff et al., 1993). More recently, Dwarki et al. (1995) reported a successful expression of B-domain-deleted factor VIII in fibroblasts and endothelial cells, as well as myoblasts, by using a MFG retroviral vector. In the present study, pdLIn vectors without any Me gave only slightly better expression levels (20-30\%) than their counterpart pdL vectors (Table 2). The differences were statistically not significant. hFIX expression levels of pdLMe4 $\beta A 280 \mathrm{hIXm} 1$ and pdLInMe $4 \beta \mathrm{A} 280 \mathrm{hIXm} 1$, which have strong internal hFIX expression activities, are very similar to each other (Table 2).

These results indicate that: (i) the $5^{\prime}$ LTR without or with the MFG-type viral intron sequence in the $\mathrm{pdL}$ and pdLIn vectors does contribute to the overall hFIX expression, but not significantly enough to affect the hFIX expression when the internal hFIX expression unit is very strong; and (ii) neither a cryptic splicing acceptor site nor the splicing acceptor site of the hIXml internal intron is likely to be used in combination with the splicing donor site in pdL-type vectors. The MFG-derived intron is only partially spliced both in the packaging cells and transduced target cells (Dwarki et al., 1995). The viral packaging sequence is contained in the MFG-derived intron sequence and, therefore, the viral RNAs of all recombinant MFG viruses must contain the intron sequence. In the targeted cells, the intron is again partially spliced (Dwarki et al., 1995). In the transient assays, the MFG-derived intron of pdLIn vectors may be partially spliced, resulting in some minor contribution to the $\mathrm{hFIX}$ production, particularly in the present of a strong internal hFIX transcriptional unit, which has a much higher expression activity than the LTR in myotubes.

When the MFG vector is used in a virus form, its transgene expression in the transduced target cells is likely elevated due to the positive effects of splicing of the intron sequence, thus resulting in an increased mRNA level for the transgene. As shown in Fig. 7 and Table 2, pdLihLXm1 $\beta$ A280Me4 has an expression activity equivalent to pdLMe $4 \beta A 280 \mathrm{hIXm} 1$ and pdLInMe $4 \beta A 280 \mathrm{hIXm1}$, supporting that, with a strong internal promoter, neither the $5^{\prime}$ LTR promoter nor the MFG-derived intron significantly affects the overall hFIX expression activity of these vectors. This was consistent with the mRNA levels (Fig. 8). This situation is much different from the original MFG vector, which uses its LTR promoter to drive expression of the inserted gene (Dranoff et al., 1993; Dwarki $e t$ al., 1995). Presence of possible cryptic elements, which may function as ATG site(s) or premature polyadenylation sites in the internal enhancer and promoter regions of the pdLIn vectors, may also minimize the effective use of mRNAs generated by the 5' LTR promoter in producing hFIX. Such possibilities, however, may be minimal, because, in the absence of Me, pdLIn vectors appear to express marginally higher levels of $h$ FIX than those of pdL vectors with various promoters (Table 2).

Unless the intron sequence of $\mathrm{hIXml}$ is retained in the ge- nomic RNA of recombinant hFIX viruses, no grossly elevated production of the hFIX mRNA due to the positive effects of such an intron can be expected in the target cells (Kurachi et al., 1995). The pdLi series of vectors was designed to test the basic vector structure that can be used to prepare a retroviral vector capable of preventing such a loss of the internal intron due to splicing in the viral packaging cells (Cone et al., 1987; Miller et al., 1988). pdLihIXm1Mgl031, with no Me, can only express hFIX at a level $21 \%$ and $27 \%$ of those of pdLInMg1031hIXm1 and pdLMg1031hIXm1, respectively. These results indicate some contribution of the $5^{\prime}$ LTR promoter activity with or without the MFG-derived intron in pdLIn and pdL vectors. Alternatively, transcripts generated by the 5' LTR may complex with the transcripts produced by the internal promoter in the reverse orientation, thus reducing the effective mRNA amount for producing factor IX. With a strong internal hFIX transcriptional unit as in pdLihIXm1Mg353Me4 or pdLihLXm1 $\beta$ A280Me4, the overall expression activities as well as mRNA levels of the pdLi-type vectors becomes indifferent from the counterpart constructs of pdLIn and pdL, indicating that the modest contribution of the 5' LTR is easily overcome (Figs. 3, 7, and 8).

These results indicate that the basic structure of the pdLitype vectors should permit us to take a full advantage of the $\mathrm{hFIX}$ minigene. It is possible that LTR-driven transcription for producing the virus genomic RNA might be affected due to the strong internal promoter activity. Promoters with Me, a differentiated muscle cell-specific enhancer, however, may function at the minimal efficiency in the fibroblast-derived packaging cells. Other possibilities, such as the presence of potential cryptic splicing donor and acceptor sites in the pdLi-type vectors cannot be ruled out (Jonsson et al., 1995). These possibilities are currently being tested in our laboratory.

\section{Effects of additional muscle specific enhancer elements}

A region spanning nucleotides $-1,351$ to $-1,050$ of the $5^{\prime}$ flanking sequence of the mouse MCK gene (designated $\mathrm{Me}$ in the present study) contains one CArG-box and two $E$ boxes and shows a strong differentiated muscle cell-specific enhancer activity (Sternberg et al., 1988). This region not only enhances the MCK promoter (Sternberg et al., 1988) but also confers enhanced muscle-specific expression of heterologous gene promoters such as simian virus 40, CMV, and c-fos (Sternberg et al., 1988; Dai et al., 1992; Martin et al., 1994). We also reported an augmentation of $\beta \mathrm{A}$ promoter activity by $\mathrm{Me}$ (Yao et al., 1994). In the present study, a systematic analysis of the enhancer effects of Me was carried out. With increasing copy numbers of Me, hFIX expression by pdL, pdLIn, and pdLi vectors with not only muscle-specific promoters such as $\mathrm{Mg}$, $\mathrm{CO} 650$, and $\alpha \mathrm{A} 775$, but also with non-muscle-specific promoters such as RSV and $\beta \mathrm{A}$, was greatly increased (Fig. 7). In general, Me affects more strongly the promoters with relatively weak basal activities, such as $\mathrm{Mg} 1031$, than those with strong activities, such as RSV and CO (Figs. 6 and 7). This, however, appears to be very much dependent with the promoter sequence, because $\beta A 280$, which has as strong a basal activity as RSV and CO650, is also enhanced as much as Mg353. Expression of pdLi-type vectors is more affected by Me than those of pdLor pdLIn-type vectors, suggesting that within the retroviral vec- 
tor frame Me primarily affects the closely linked internal promoter; the $5^{\prime}$ LTR located at a distant position is less affected.

\section{Expression activities of different promoters}

Myogenin is one of the well-defined muscle-specific transcriptional factors (Edmondson et al., 1992; Schwarz et al., 1992). The $\mathrm{Mg}$ promoter has a strong specificity for differentiated muscle cells and was used in the present study as a model promoter for testing various conditions. As shown with pdLInMg1031hIXml, a long form of myogenin promoter, Mg1031, shows approximately 10-fold higher level of hFIX expression in myotubes than in myoblasts in good agreement with the previous observations (Edmondson et al., 1992). In the present study, the short form of the myogenin promoter $\mathrm{Mg} 353$ not only retained the differentiated muscle cell specific activity, but its expression activity was also higher by about 1.6-fold than that of $\mathrm{Mg} 1031$ (Figs. 6 and 7). These observations suggest that the region spanning nucleotides -353 to $-1,031$, which is present only in $\mathrm{Mg} 1031$, and contains additional $\mathrm{E}$ boxes, contributes rather negatively to the transcriptional activity. This difference between $\mathrm{Mg} 1031$ and $\mathrm{Mg} 353$ was observed regardless of the vector type (pdL, pdLIn, or pdLi) and presence or absence of Me (see also Figs. 6 and 7). Interestingly, a short form of the calf $\mathrm{CO}$ promoter, CO650, also gave a substantially higher expression activity than that of the long form, CO1250 (Table 2). The proximal regions up to nucleotide -353 in the $\mathrm{Mg}$ promoter and up to nucleotide -588 in the $\mathrm{CO}$ promoter contain multiple muscle-specific enhancer elements (Edmondson et al., 1992; Lomax et al., 1995). It is not known at the present time why the longer forms, which contain additional enhancer elements, produce lower activities than the short form. The longer forms may also contain hitherto unidentified silencer elements. Four Me copies increased the expression activity of $\mathrm{CO} 650$ by only 1.5 -fold as observed for pdLInCO650hIXm1 and pdLInMe4CO650hDXm1 (Fig. 7A, Table 2). A similar, rather poor enhancement of the RSV promoter (1.6-fold) with Me was also observed. $\beta A 280$ has a basal activity equivalent to RSV and $\mathrm{CO650}$ promoters, but its activity was enhanced three-fold with $\mathrm{Me} 4$, equivalent to that of Mg353 (3.2-fold) (Fig. 7A, Table 2). These results suggest that the enhancer activity of $\mathrm{Me}$ is dependent on the promoter sequence in addition to the vector frame context as discussed above. $\alpha \mathrm{A}$, another muscle-specific promoter, is as strong as $\mathrm{Mg} 1031$ in the presence of Me4.

Among promoters tested, both $\beta \mathrm{A} 280$ and $\beta \mathrm{A} 200$ with Me4 consistently produce hFIX in muscle cells at the highest level in all three vector frames. It is important to find that $\beta A 200$, which is modified from $\beta A 280$, still has an expression activity comparable to $\beta A 280$. Presence of an increasing copy number of $\mathrm{Me}$ in the vector results in a higher hFIX expression. However, to minimize potential rearrangements of the vector DNA in the process of gene transfer and chromosomal integration, as small as two Me copies, and not more than four copies, may be preferred. These multiple Me copies insure a substantial increase in hFIX production in skeletal muscle cells.

\section{Optimal basic structure of hFIX retroviral vector for skeletal muscle cells}

Through the systematic analyses carried out and as discussed above, we conclude that the basic structure of a retroviral vec- tor for achieving an optimal hFIX expression in differentiated muscle cells should have a pdLi vector frame with an internal hFIX expression cassette composed of two (and no more than four) Me copies, $\beta A 200$ and hIXm2. pdLihLXm2 $\beta A 200 \mathrm{Me} 2$ and pdLihIXm2 2 A200Me 4 satisfy all of the conditions considered for maximizing hFIX expression. In transient assays, pdLihIXm2 $2 \beta A 200 \mathrm{Me} 4$ expressed hFLX at levels 15 - or 30 -fold higher than those of the previous-generation retroviral vectors, LIXSN or pdLMe $2 \beta A 280 \mathrm{hIX}$, respectively (Table 2 ). These refinements made to the basic structure of the vector insure not only the enhanced muscle-specific, high-level expression of hFIX in the target cells, but also possible preparation of recombinant virus at a high yield in the packaging cells. The $3^{\prime}$ LTR with its enhancer deleted should assure a minimal interference of hFIX expression directed by the reversed internal expression unit in the target cells. Preparation of recombinant

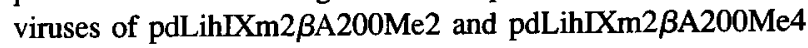
are in progress.

The internal hFIX expression unit as well as each structural component such as enhancer, promoter, and hFIX minigene of the vectors described in this study have been constructed as versatile cassettes. They can be easily transferred into various different types of vector systems such as adenovirus, AAV, or nonviral vector systems, and their enhancer, promoter, or gene can also be easily exchanged with others to target not only the FIX gene but also various other genes of interest into different cell types and tissues. For example, proteins were produced at levels as high as hFIX by replacing the $h I X m 1$ sequence in pdLihLXm1 $\beta$ A280Me4 with those of protein $\mathrm{C}$ or hirudin cDNA (unpublished data).

\section{ACKNOWLEDGMENTS}

We thank Dr. M. Lomax for providing a skeletal cytochrome oxidase gene clone. This work was in part supported by National Institutes of Health grants HL 53713 and HL 38644 to K.K. and funds from the University of Michigan Multipurpose Arthritis and Musculoskeletal Disease Center (NIH-5-P60-AR20557) and the General Clinical Research Center (NIH-M01-RR00042). J.-M.W. is a recipient of the fellowship of the Education Commission of P.R. of China.

\section{REFERENCES}

ACSADI, G., MASSIE, B., and JANI, A. (1995). Adenovirus-mediated gene transfer into striated muscles. J. Mol. Med. 73, 165-180. ANSON, D.S., and OCCHIODORO, T. (1994). Transcriptional activity of the CD45 gene promoter in retroviral vector constructs. Biochim. Biophys. Acta 1219, 81-88.

BANSAL, V., MOWERY-RUSHTON, P., LUCHT, L., LI, J., BAHNSON, A., WATKINS, S.C., and BARRANGER, J.A. (1994). Transduction, expression, and secretion of human glucocerebrosidase by murine myoblasts. Ann. N.Y. Acad. Sci. 716, 307-319.

BAQUE, S., NEWGARD, C.B., GERARD, R.D., GUINOVART, J.J., and GOMEZ-FOIX, A.M. (1994). Adenovirus-mediated delivery into myocytes of muscle glycogen phosphorylase, the enzyme deficient in patients with glycogen-storage disease type V. Biochem. J. 304 (pt. 3), 1009-1014.

BARR, E., and LEIDEN, J.M. (1991). Systemic delivery of recombi- 
nant proteins by genetically modified myoblasts. Science 254 , 1507-1509.

CONE, R.D., WEBER-BENAROUS, A., BAORTO, D., and MULLIGAN, R.C. (1987). Regulated expression of a complete human $\beta$ globin gene encoded by a transmissible retrovirus vector. Mol. Cell Biol. 7, 887-897.

DAHLER, A., WADE, R.P., MUSCAT, G.E., and WATERS, M.J. (1994). Expression vectors encoding human growth hormone (hGH) controlled by human muscle-specific promoters: Prospects for regulated production of hGH delivered by myoblast transfer or intravenous injection. Gene 145, 305-310.

DAI, Y., ROMAN, M., NAVIAUX, R.K., and VERMA, I.M. (1992). Gene therapy via primary myoblasts: Long-term expression of factor IX protein following transplantation in vivo. Proc. Natl. Acad. Sci. USA 89, 10892-10895.

DAI, Y., SCHWARZ, E.M., GU, D., ZHANG, W.W., SARVETNICK, N., and VERMA, I.M. (1995). Cellular and humoral immune responses to adenoviral vectors containing factor IX gene: Tolerization of factor IX and vector antigens allows for long-term expression. Proc. Natl. Acad. Sci. USA 92, 1401-1405.

DAVIS, H.L., DEMENEIX, B.A., QUANTIN, B., COULOMBE, J., and WHALEN, R.G. (1993a). Plasmid DNA is superior to viral vectors for direct gene transfer into adult mouse skeletal muscle. Hum. Gene Ther. 4, 733-740.

DAVIS, H.L., WHALEN, R.G., and DEMENEIX, B.A. (1993b) Direct gene transfer into skeletal muscle in vivo: Factors affecting efficiency of transfer and stability of expression. Hum. Gene Ther. 4, 151-159.

DHAWAN, J., PAN, L.C., PAVLATH, G.K., TRAVIS, M.A., LANCTOT, A.M., and BLAU, H.M. (1991). Systemic delivery of human growth hormone by injection of genetically engineered myoblasts. Science 254, 1509-1512.

DRANOFF, G., JAFFEE, E., LAZENBY, A., GOLUMBEK, P., LEVITSKY, H., BROSE, K., JACKSON, V., HAMAKA, H., PARDOLL, D., and MULLIGAN, R.C. (1993). Vaccination with irradiated tumor cells engineered to secrete murine granulocyte-macrophage colony-stimulating factor stimulates potent, specific, and long-lastmg anti-tumor immunity. Proc. Natl. Acad. Sci. USA 90, 3539-3543.

DWARKI, V.J., BELLONI, P., NIJJAR, T., SMITH, J., COUTO, L., RABIER, M., CLIFT, S., BERNS, A., and COHEN, L.K. (1995). Gene therapy for hemophilia A: production of therapeutic levels of human factor VIII in vivo in mice. Proc. Natl. Acad. Sci. USA 92, 1023-1027.

EDMONDSON, D.G., CHENG, T.C., CSERJESI, P., CHAKRABORTY, T., and OLSON, E.N. (1992). Analysis of the myogenin promoter reveals an indirect pathway for positive auto regulation mediated by the muscle-specific enhancer factor MEF-2. Mol. Cell. Biol. 12, 3665-3677.

EUSTICE, D.C., FELDMAN, P.A., COLBERG-POLEY, A.M., BUCKERY, R.M., and NEUBAUER, R.H. (1991). A sensitive method for the detection of $\beta$-galactosidase in transfected mammalian cells. BioTechniques 11, 739-742.

GROSSMAN, M., RAPER, S.E., KOZARSKY, K., STEIN, E.A., ENGELHARDT, J.F., MULLER, D., LUPIEN, P.J., and WILSON, J.M. (1994). Successful ex vivo gene therapy directed to liver in a patient with familial hypercholesterolaemia. Nat. Genet. 6, 335-341.

HAMAMORI, Y., SAMAL, B., TIAN, J., and KEDES, L. (1995). Myoblast transfer of human erythropoietin gene in a mouse model of renal failure. J. Clin. Invest. 95, 1808-1813.

HERBOMEL, P., BOURACHOT, B., and YANIV, M. (1984). Two distinct enhancers with different cell specificities coexist in the regulatory region of polyoma. Cell 39, 653-662.

JAO, S., GUREVICH, V., and WOLFF, J.A. (1993). Long-term correction of rat model of Parkinson's disease by gene therapy. Nature $362,450-453$.

JONSSON, J.J., HABEL, D.E., and McIVOR, R.S. (1995). Retrovirus- mediated transduction of an engineered intron-containing purine nucleoside phosphorylase gene. Hum. Gene Ther. 6, 611-623.

KOST, T.A., THEODORAKIS, N., and HUGHES, S.H. (1983). The nucleotide sequence of the chick cytoplasmic $\beta$-actin gene. Nucleic Acids Res. 11, 8287-8301.

KURACHI, S., HITOMI, Y., FURUKAWA, M., and KURACHI, K. (1995). Role of intron $I$ in expression of the human factor IX gene. J. Biol. Chem. 270, 5276-5281.

LOMAX, M.I., RIGGS, P.K., and WOMACK, J.E. (1995). Structure and chromosomal location of the bovine gene for the heart muscle isoform of cytochrome c oxidase subunit VIII. Mamm. Genome 6, 118-122.

MANTHORPE, M., CORNEFERT-JENSEN, F., HARTIKKA, J., FELGNER, J., RUNDELL, A., MARGALITH, M., and DWARKI, V. (1993). Gene therapy by intramuscular injection of plasmid DNA: Studies on firefly luciferase gene expression in mice. Hum. Gene Ther. 4, 419-431.

MARTIN, K.A., WALSH, K., and MADER, S.L. (1994). The mouse creatine kinase paired E-box element confers muscle-specific expression to a heterologous promoter. Gene 142, 275-278.

MILLER, A.D. (1992a). Human gene therapy comes of age. Nature $357,455-460$.

MILLER, A.D. (1992b). Retroviral vectors. Curr. Top. Microbiol. Immunol. 158, 1-24.

MILLER, A.D., BENDER, M.A., HARRIS, E.A.S., KALEKO, M., and GELINAS, R.E. (1988). Design of retrovirus vectors for transfer and expression of the human $\beta$-globin gene. J. Virol. 62, 4337-4345.

OHASHI, T., BOGGS, S., ROBBINS, P., BAHNSON, A., PATRENE, K., WEI, F.S., WEI, J.F., LI, J., LUCHT, L., FEI, Y., CLARK, S., KIMAK, M., HE, H., MOWERY-RUSHTON, P., and BARRANGER, J.A. (1992). Efficient transfer and sustained high expression of the human glucocerebrosidase gene in mice and their functional macrophages following transplantation of bone marrow transduced by a retroviral vector. Proc. Natl. Acad. Sci. USA 89, 11332-11336.

PALMER, T.D., ROSMAN, G.J., OSBORNE, W.R., and MILLER, A.D. (1991). Genetically modified skin fibroblasts persist long after transplantation but gradually inactivate introduced genes. Proc. Natl. Acad. Sci. USA 88, 1330-1334.

PETROPOULOS, C.J., PAYNE, W., SALTER, D.W., and HUGHES, S.H. (1992). Appropriate in vivo expression of a muscle-specific promoter by using avian retroviral vectors for gene transfer. J. Virol. 66, 3391-3397.

RAGOT, T., VINCENT, N., CHAFEY, P., VIGNE, E., GILGENKRANTZ, H., COUTON, D., CARTAUD, J., BRIAND, P., KAPLAN, J.C., PERRICARDET, M., and KAHN, A. (1993). Efficient adenovirus-mediated transfer of a human minidystrophin gene to skeletal muscle of mdx mice. Nature 361, 647-650.

RANDO, T.A., and BLAU, H.M. (1994). Primary mouse myoblast purification, characterization, and transplantation for cell-mediated gene therapy. J. Cell. Biol. 125, 1275-1287.

SALVATORI, G., FERRARI, G., MEZZOGIORNO, A., SERVIDEI, S., COLETTA, M., TONALI, P., GIAVAZZI, R., COSSU, G., and MAVILIO, F. (1993). Retroviral vector-mediated gene transfer into human primary myogenic cells leads to expression in muscle fibers in vivo. Hum. Gene Ther. 4, 713-723.

SCHARFMANN, R., AXELROD, J.H., and VERMA, I.M. (1991). Long-term in vivo expression of retrovirus-mediated gene transfer in mouse fibroblast implants. Proc. Natl. Acad. Sci. USA 88, $4626-4630$.

SCHWARZ, J.J., CHAKRABORTY, T., MARTIN, J., ZHOU, J.M., and OLSON, E.N. (1992). The basic region of myogenin cooperates with two transcription activation domains to induce muscle-specific transcription. Mol. Cell. Biol. 12, 266-275.

STERNBERG, E.A., SPIZZ, G., PERRY, W.M., VIZARD, E., WEL, T., and OLSON, E.N. (1988). Identification of upstream and intra- 
genic regulatory elements that confer cell-type-restricted and differentiation-specific expression on the muscle creatine kinase gene. Mol. Cell. Biol. 8, 2896-2909.

TAYLOR, A., ERBA, H.P., MUSCAT, G.E.O., and KEDES, L. (1988). Nucleotide sequence and expression of the human skeletal $\alpha$-actin gene: Evolution of functional regulatory domains. Genomics 3, 323-336.

TRIVEDI, R.A., and DICKSON, G. (1995). Liposome-mediated gene transfer into normal and dystrophin-deficient mouse myoblasts. J. Neurochem. 64, 2230-2238.

VINCENT, N., RAGOT, T., GILGENKRANTZ, H., COUTON, D., CHAFEY, P., GREGOIRE, A., BRIAND, P., KAPLAN, J.C., KAHN, A., and PERRICAUDET, M. (1993). Long-term correction of mouse dystrophic degeneration by adenovirus-mediated transfer of a minidystrophin gene. Nat. Genet. 5, 130-134.

VITADELLO, M., SCHIAFFINO, M.V., PICARD, A., SCARPA, M., and SCHIAFFINO, S. (1994). Gene transfer in regenerating muscle. Hum. Gene Ther. 5, 11-18.

WEBSTER, C., PAVLATH, G.K., PARKS, D.R., WALSH, F.S., and BLAU, H.M. (1988). Isolation of human myoblasts with the fluorescence-activated cell sorter. Exp. Cell Res. 174, 252-265.

WILSON, J.M., JOHNSTON, D.E., JEFFERSON, D.M., and MULLIGAN, R.C. (1988). Correction of the genetic defect in hepatocytes from the Watanabe heritable hyperlipidemic rabbit. Proc. Natl. Acad. Sci. USA 85, 4421-4425.
YAO, S.N., and KURACHI, K. (1992). Expression of human factor IX in mice after injection of genetically modified myoblasts. Proc. Natl. Acad. Sci. USA 89, 3357-3361.

YAO, S.N., and KURACHI, K. (1993). Implanted myoblasts not only fuse with myofibers but also survive as muscle precursor cells. J. Cell Sci. 105, 957-963.

YAO, S.N., WILSON, J.M., NABEL, E.G., KURACHI, S., HACHIYA, H.L., and KURACHI, K. (1991). Expression of human factor IX in rat capillary endothelial cells: Toward somatic gene therapy for hemophilia B. Proc. Natl. Acad. Sci. USA 88, 8101-8105.

YAO, S.N., SMITH, K.J., and KURACHI, K. (1994). Primary myoblast-mediated gene transfer: persistent expression of human factor LX in mice. Gene Ther. 1, 99-107.

$$
\begin{array}{r}
\text { Address reprint requests to: } \\
\text { Dr. Kotoku Kurachi } \\
\text { Department of Human Genetics } \\
\text { University of Michigan Medical School } \\
\text { Medical Science II M4708 } \\
\text { Ann Arbor, MI 48109-0618 }
\end{array}
$$

Received for publication February 20, 1996; accepted after revision June 26, 1996. 
1. Marie-Helene Rodriguez, Jean-Luc Plantier, Nathalie Enjolras, Muriel Rea, Marylene Leboeuf, Georges Uzan, Claude Negrier. 2005. Biosynthesis of FVIII in megakaryocytic cells: improved production and biochemical characterization. British Journal of Haematology 127:5, 568-575. [CrossRef]

2. Jianhua Huang, Yoshinori Ito, Masayoshi Kobune, Katsunori Sasaki, Kiminori Nakamura, Hironari Dehari, Kazuhiro Takahashi, Katsuya Ikeda, Hiroaki Uchida, Kazunori Kato, Hirofumi Hamada. 2003. Myocardial injection of CA promoter-based plasmid mediates efficient transgene expression in rat heart. The Journal of Gene Medicine 5:10, 900-908. [CrossRef]

3. Carol H. Miao , Xin Ye , Arthur R. Thompson . 2003. High-Level Factor VIII Gene Expression In Vivo Achieved by Nonviral Liver-Specific Gene Therapy VectorsHigh-Level Factor VIII Gene Expression In Vivo Achieved by Nonviral Liver-Specific Gene Therapy Vectors. Human Gene Therapy 14:14, 1297-1305. [Abstract] [PDF] [PDF Plus]

4. Paul H. Krebsbach, Kezhong Zhang, Ajay K. Malik, Kotoku Kurachi. 2003. Bone marrow stromal cells as a genetic platformfor systemic delivery of therapeutic proteinsin vivo: human factorIX model. The Journal of Gene Medicine 5:1, 11-17. [CrossRef]

5. G. Hortelano, L. Wang, N. Xu, F. A. Ofosu. 2001. Sustained and therapeutic delivery of factor IX in nude haemophilia B mice by encapsulated C2C12 myoblasts: concurrent tumourigenesis. Haemophilia 7:2, 207-214. [CrossRef]

6. Dario COLETTI, Simonetta PALLESCHI, Leopoldo SILVESTRONI, Francesco TOMEI, Mario MOLINARO, Sergio ADAMO. 2000. Surface Remodeling Associated with Vasopressin-Induced Membrane Traffic in L6 Myogenic Cells. Archives of Histology and Cytology 63:5, 441-449. [CrossRef]

7. Jonathan E. Loeb, Wendy S. Cordier, Matthew E. Harris, Matthew D. Weitzman, Thomas J. Hope . 1999. Enhanced Expression of Transgenes from Adeno-Associated Virus Vectors with the Woodchuck Hepatitis Virus Posttranscriptional Regulatory Element: Implications for Gene TherapyEnhanced Expression of Transgenes from Adeno-Associated Virus Vectors with the Woodchuck Hepatitis Virus Posttranscriptional Regulatory Element: Implications for Gene Therapy. Human Gene Therapy 10:14, 2295-2305. [Abstract] [PDF] [PDF Plus]

8. Gonzalo Hortelano, Nong Xu , Andrea Vandenberg, Jesus Solera, Patricia L. Chang, Frederick A. Ofosu . 1999. Persistent Delivery of Factor IX in Mice: Gene Therapy for Hemophilia Using Implantable MicrocapsulesPersistent Delivery of Factor IX in Mice: Gene Therapy for Hemophilia Using Implantable Microcapsules. Human Gene Therapy 10:8, 1281-1288. [Abstract] [PDF] [PDF Plus]

9. J. Jarmo Wahlfors, Richard A. Morgan . 1999. Production of Minigene-Containing Retroviral Vectors Using an Alphavirus/Retrovirus Hybrid Vector SystemProduction of Minigene-Containing Retroviral Vectors Using an Alphavirus/Retrovirus Hybrid Vector System. Human Gene Therapy 10:7, 1197-1206. [Abstract] [PDF] [PDF Plus]

10. Tatiana I. Samoylova, Bruce F. Smith. 1999. Elucidation of muscle-binding peptides by phage display screening. Muscle \& Nerve 22:4, 460-466. [CrossRef]

11. Wang Hongwei, Bao Yun, Xin Yongna, Yang Xiaoqin, Shi Qian, Lu Daru, Qiu Xinfang, Xue Jinglun. 1998. Construction and expression of inverted configuration of retroviral vector containing intron 1 of hFIX. Chinese Science Bulletin 43:4, 315-318. [CrossRef] 